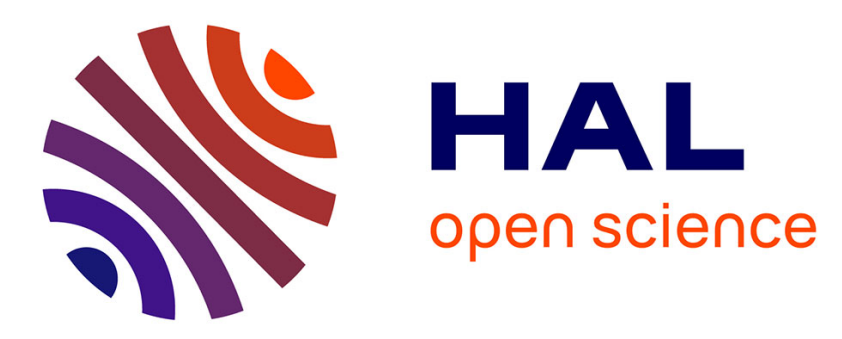

\title{
An Info*Engine based architecture to support interoperability with Windchill system
}

Mohamed Anis Dhuieb, Farouk Belkadi, Florent Laroche, Alain Bernard

\section{To cite this version:}

Mohamed Anis Dhuieb, Farouk Belkadi, Florent Laroche, Alain Bernard. An Info*Engine based architecture to support interoperability with Windchill system. 7th International Conference on Interoperability for Enterprises Sytems and Applications. Workshop Standardisation Developments for Enterprise Interoperability and the Manufacturing Service Domain, Mar 2014, Albi, France. hal01066440

\section{HAL Id: hal-01066440 \\ https://hal.science/hal-01066440}

Submitted on 20 Sep 2014

HAL is a multi-disciplinary open access archive for the deposit and dissemination of scientific research documents, whether they are published or not. The documents may come from teaching and research institutions in France or abroad, or from public or private research centers.
L'archive ouverte pluridisciplinaire $\mathbf{H A L}$, est destinée au dépôt et à la diffusion de documents scientifiques de niveau recherche, publiés ou non, émanant des établissements d'enseignement et de recherche français ou étrangers, des laboratoires publics ou privés. 


\title{
An Info*Engine based architecture to support interoperability with Windchill system
}

\author{
Mohamed Anis Dhuieb ${ }^{*}$ - Farouk Belkadi ${ }^{*}$ - Florent Laroche ${ }^{*}$ \\ - Alain Bernard*
}

*LUNAM Université, Institut de Recherche en Communications et Cybernétique de Nantes, Ecole centrale de Nantes. 1 rue de la Noë, 44300 Nantes

Mohamed-anis.dhuieb@irccyn.ec-nantes.fr

\begin{abstract}
This paper deals with the complex issue of interoperability methods and technologies especially in PLM field. Windchill is one of the most popular PLM software proposing robust solutions to support communication with external information systems. The purpose of this paper is to prospect the interoperability mechanisms offered by PTC editor as a solution to interoperability issue. A new interoperability framework is proposed as a Webservice based solution using the capacities embedded in the Windchill Info*Engine mechanisms and J2EE application technology.
\end{abstract}

KEYWORDS: Interoperability, PLM, Windchill, Webservices, Info*Engine 
An Info*Engine based architecture to support automatic interoperability

\section{Introduction}

According to (Srinivansan, 2011), the scope and definition of PLM are expanding and maturing to meet the demands of an increasingly complex network of industrial partners spread globally and bound together by common business objectives. These partners have to collaborate by sharing and exchanging products and processes information, and integrate their engineering and business decision support systems. For this need, each partner needs to develop the capacity of their information systems to communicate easily with the other partners systems. In this context, interoperability becomes an important challenge for the ICT scientific and industrial community (Stanescu, 2009). Another definition is given by The United States Department of Defense, which proposes an extension of the interoperability concept to the ability to exchange services between various systems and organizations. Generally, three scopes of interoperability are distinguished with different terms and definitions. For instance: the Conceptual interoperability that concerns the definition of concepts and semantic supporting the communication between data and knowledge models; the Organizational interoperability, which focus on the connection between processes and the Technical interoperability that deals with technological issues to support data exchange between software applications (Ruggaber, 2005) (Bellatreche et al., 2006).

This work deals with the last category of interoperability and aims to investigate the advantages given by the PTC Info*Engine framework for communication with PLM (Product Lifecycle Management) system. PLM is a collaborative backbone allowing people throughout extended enterprises to work together more efficiently (Choi et al., 2002). The Enterprise Information System (EIS) results from the integration between Enterprise Resource Planning (ERP), Product Data Management (PDM) and other related systems such as ComputerAided Design (CAD) and Customer Relationship Management (CRM). Due to the collaborative character and the main role consisting of data exchange throughout heterogeneous information systems, PLM is one of major field in which interoperability have an important contribution (Song et al., 2006).

First, we present a state of the art about the current technical developments used to support communication between ICT systems. Then, we present a new architecture based on Info*Engine integration engine and Webservice technology and proposed as a solution to support automatic import/export operations in the case of Windchill system. The following section presents an overview about the problematic of interoperability. A focus is made on the recent developments concerning the technical interoperability. The third section presents a description of the different interoperability mechanisms offered by Windchill that is one of most popular PLM systems, developed by PTC Company. The fourth section presents the proposed technical architecture and the developed interface to ensure the automatic communication with Windchill server. 


\section{Literature survey about interoperability}

In addition to the term definition, another important characteristic of the interoperability concept concerns the variety of classification according to the interoperability goal, the type of interoperable items or also the nature of methods and technologies that are used for the interoperability strategy.

In practice, three major approaches are currently used to support the data exchange between Computer Aided applications (CAx). The first category uses a standard based mechanism to guarantee the semantic translation between heterogeneous models. Several standards are used in the literature such as the project ATHENA, in which Process standards (ISO15288, CMII) and product standards (STEP: STandard for the Exchange of Product model data. Ex: AP214, 233, 209, 239) have been studied. IGES (Initial Graphics Exchange Specifications) and DXF (Drawing Exchange Format) standards are also used to manage the geometric data of the product. The second category uses the ontology and the Semantic Web technologies to achieve the data mapping between heterogeneous software. Several studies implementing different approaches to product design have been conducted on Ontology, as standard for data exchange between design and other engineering activities in collaborative tasks. The last category use dynamic interfaces, based on API Standards (Application Program Interface), to guarantee the communication between software. In this kind of interoperability mechanism, software integration is fulfilled through the web services technologies to support the distribution of heterogeneous information between members of a project team. "OMG PDM Enablers" based on middleware technologies and "PLM Services" are Web technologies developed to support communication between PLM systems.

Owing to the recent facilities offered by the World-Wide Web technologies, Web Based Modeling and Simulation has been proposed to support the modelling and simulation tasks in a PLM context. The use of this concept is facilitated by the MDE (Model Driven Engineering) technology dedicated to the formulation, the formalization and the automation of the development process.

\section{Info-Engine based framework for interoperability}

Windchill integration with other enterprise's applications requires the use of low-level APIs and complex application adapters. Supporting new integration scenarios is a labor task and requires strong development skills. For this need, Windchill Info*Engine server provides mechanisms for retrieving and manipulating the data that users or custom applications want to view or receive from the PLM server. The next section presents the technical architecture of the proposed interoperability framework base on Info*Engine mechanisms. 


\subsection{Technical architecture}

As it is shown in figure 1, the proposed architecture is based on Info*Engine Java 2 Enterprise Edition (J2EE) connector, that is an implementation of J2EE Connector Architecture (JCA). JCA was designed to supply standard implementation for interaction between $\mathrm{J} 2 \mathrm{EE}$ application servers and enterprise information systems (EIS). The Info*Engine J2EE connector uses SOAP protocol to allow communication between Info*Engine and the two modules of the interoperability application. For instance, J2EE application server and associated client application are developed as an integrated solution for the interoperability purpose.

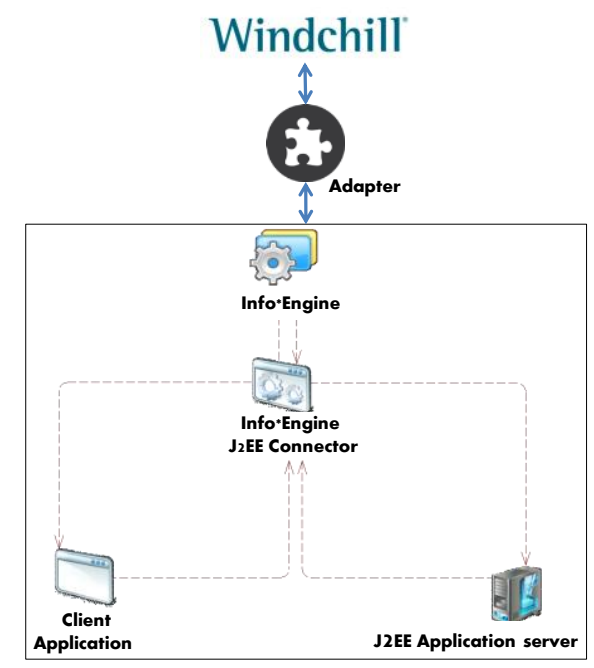

Figure 1. The Info*Engine based architecture

The client application is deployed on Oracle $11 \mathrm{~g}$ application server. Using the client application, the user can perform different interoperability actions like creating/deleting an object in the Windchill server or even adding a link between a part and a document. The J2EE application server supports the interpretation and execution of actions prescripted by the client application. Otherwise, Info*Engine is directly interfaced with Windchill application by means of the Native Adapters component. The implementation of the proposed solution is achieved by a set of interactions between the different components of Info*Engine framework and the interoperability client application. As it is shown in figure 1, the client application communicates directly with the Info*Engine SOAP Servlet that catch and process SOAP requests and send the required information to the client application. For this need, the SOAP servlet invokes tasks execution on the SAK (Service Access Kit), which is an API facilitating the development of Java applications, including JSP pages, using Info*Engine functions and features. During task execution, SAK interacts with the naming service in order to instantiate required services. With the Naming Service, SAK can identify in the LDAP directory all network addresses 
and configuration properties. In the meantime, the client application has a direct connection to the SAK and the naming services to extract the services parameters and code interpretation respectively, which are required for the definition of the Webservice request.

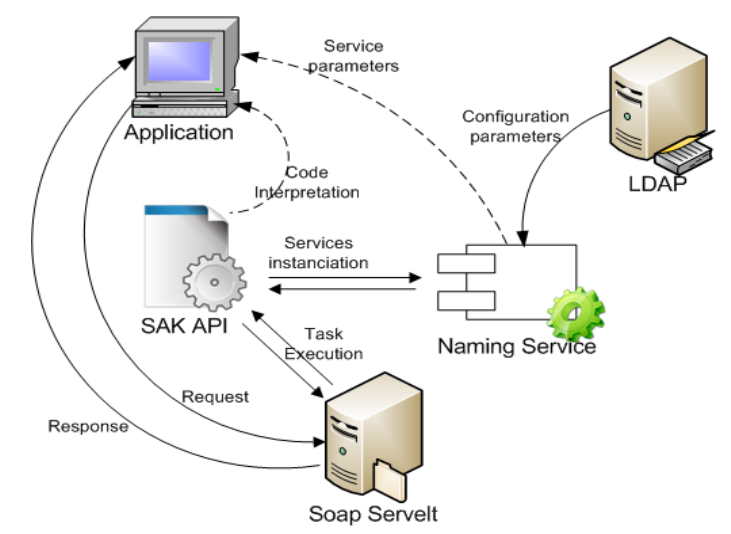

Figure 2. Internal and external interactions in the proposed framework

\subsection{Demonstrator}

Based on the technical architecture presented above, we developed a Webservice based application. Figure 3 illustrates the interactions schema between the user, the interoperability client application and Windchill, throughout the Info*Engine framework.

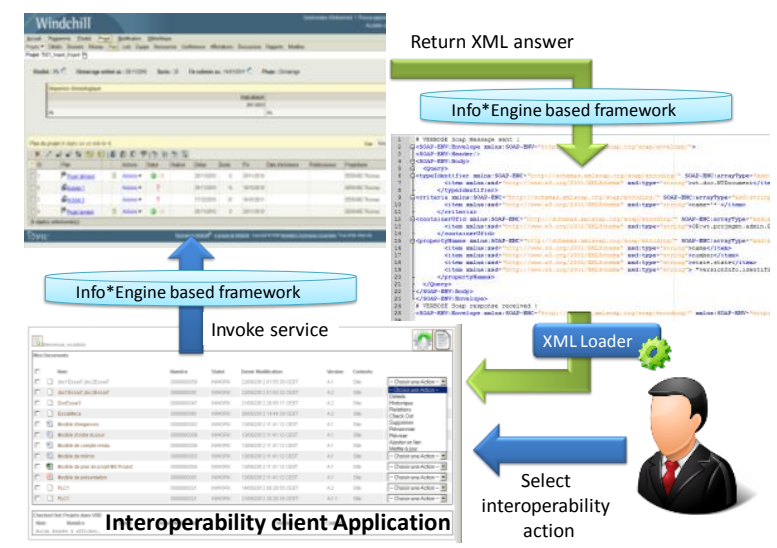

Figure 3. Webservice based application

After the user identification by entering his Windchill login and password, the client application receives from Windchill a list of different objects that are associated to the user role in the database. At the right of the interface, a set of 
authorized actions are proposed to the user to perform on the Windchill server throughout the Info*Engine based framework. For instance, the user can obtain more details about the selected object, check out, modify or delete this object or also, creates link with other Windchill objects.

When the user validates his/her action, the client application invoke the corresponding service(s) on the Info*Engine framework according to the general interaction schema presented in figure 3 . Then, the Windchill send the answer in a predefined XML file to the Info*Engine framework.

\section{Conclusion}

This framework is a first step for the development of an integrated connector for Windchill server. The main utility of this connector is to handle process and product knowledge to be integrated in a virtual decision support system. Using this framework, the user can benefit from relating an external application with Windchill allowing the application to create and manipulate parts and documents in Windchill. Further work will aim at the definition of robust loader tool to support the interpretation of Windchill responses in a knowledge management perspective.

The first results of the interoperability tests performed on the proposed framework illustrate a high level of reactivity to different requests. The main advantages of the proposed architecture is that it offer a large possibilities to pilot the communication with Windchill system through an external third-party application while ensuring a coherence with internal mechanisms of Windchill, since it exploits directly the internal components of Windchill.

\section{References}

Srinivasan, V. (2011). An integration framework for product lifecycle management. Computer-aided design, 43(5), 464-478.

Stanescu A.M., Dumitrache., Caramihai S.I., Moisescu M.A., Sacala I.S.,(2009) ,The Grand Unification: Emerging Sciences to Support Interoperability Based Complex Adaptive Systems in Intelligent Manufacturing ", sème Congrès international de Génie Industriel.

DoD, United States Department of Defence, Joint Publication 1-02, "Department of Defence Dictionary of Military and Associated Terms", 12th April 2001; p270.

Choi, G.H., Mun, D., Han, S. (2002). Exchange of CAD Part Models Based on the MacroParametric Approach, International Journal of CAD/CAM Vol. 2, No. 1, pp. 13--21.

Ruggaber R., (2005), ATHENA - Advanced Technologies for Interoperability of Heterogeneous Enterprise Networks and their Application, International Conference on Interoperability of Enterprise Software and Applications, Geneva, Switzerland.

Bellatreche, L., Xuan, D.N., Pierra, G., \& Dehainsala, H. (2006). Contribution of Ontologybased Data Modeling to Automatic Integration of Electronic Catalogues within Engineering Databases, Computers in Industry Vol. 57, No. 8-9, pp. 711--724.

Song H., Roucoules L., Eynard B., Lafon P., (2006). Interoperability between Cooperative Design Modeller and a CAD System: Software Integration versus Data Exchange, International Journal for Manufacturing Science \& Production, Vol. 7, No. 2, pp. 139--149. 